\title{
Expression of P16 biomarker in squamous cell carcinoma of uterine cervix and its association with clinico-pathological parameters: A cross-sectional study
}

\author{
Kalyani R. ${ }^{1}{ }^{*}$, , Raghuveer C.V. ${ }^{1}$, Sheela S.R. ${ }^{2}$
}

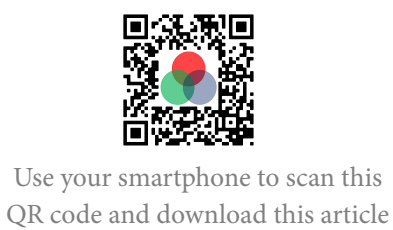

${ }^{1}$ Department of Pathology, Sri Devaraj Urs Medical College, Sri Devaraj Urs Academy of Higher Education and Research, Tamaka, Kolar, 563101, Karnataka, India

${ }^{2}$ Obstretics \& Gynecology, Sri Devaraj Urs Medical College, Sri Devaraj Urs Academy of Higher Education and Research, Tamaka, Kolar, 563101, Karnataka, India

\section{Correspondence}

Kalyani R., Department of Pathology, Sri Devaraj Urs Medical College, Sri Devaraj Urs Academy of Higher Education and Research, Tamaka, Kolar, 563101, Karnataka, India

Email: drkalyanir@rediffmail.com

\section{History}

- Received: Jun-28-2020

- Accepted: Aug-28-2020

- Published: Sep-25-2020

DOI : 10.15419/bmrat.v7i9.626

\section{Check for updates}

\section{Copyright}

(๑) Biomedpress. This is an openaccess article distributed under the terms of the Creative Commons Attribution 4.0 International license.

\begin{abstract}
Introduction: Cervical cancer is the most common cancer among females. P16 is the surrogate marker for cervical carcinoma. This study aimed to evaluate the association of P16 marker with clinic-pathological parameters in squamous cell carcinoma of uterine cervix. Methods: This was a cross-sectional study. Histological confirmed cases of squamous cell carcinoma (SCC) of cervix were considered. All cases were evaluated for IHC P16 expression as per lower anogenital squamous terminology (LAST) criteria and correlated with clinico-pathological parameters. The data was analyzed by SPSS software version 22. Results: Out of 75 cases, P16 biomarker expression was block positive, ambiguous and negative in 67 (89.3\%), 5 (6.6\%), and 3 (4\%) cases, respectively. There was a significant association between P16 expression and age $(p=0.005)$. All cases between $30-59$ years of age showed block positivity. There was no significant association between P16 expression and age at marriage $(p=0.951)$, age at menopause $(p=0.311)$, parity $(p=0.554)$, clinical symptoms/signs, stage of disease $(p=0.28)$, or histopathological grade $(p=0.877)$. Maximum expression was seen between 40-44 years. Moreover, all cases having 1 \& 2 parity showed block positivity and all stage I cases showed block positivity. Conclusion: P16 biomarker was significantly expressed in cervical cancers of the relatively younger age group and those with early stage of disease.

Key words: Cervix, clinico-pathological parameters, P16 biomarker, squamous cell carcinoma of cervix
\end{abstract}

\section{INTRODUCTION}

Cervical cancer is the third most common cancer in women worldwide with a global prevalence of $11.7 \%$, and accounts as the $5^{\text {th }}$ most common cause of cancerrelated deaths. Its annual estimated global incidence is 500,000 cases, with India accounting for approximately 100,000 cases $^{1-3}$. Cervical cancer is the second common cancer in underdeveloped countries among females ${ }^{1}$. The Human Papilloma Virus (HPV) is a proven etiological factor ${ }^{1,3,4}$. The age range for cervical cancer is reported to be 27-80 years with mean age of 54.2 years; the maximum cases have been noted between 41-60 years of age ${ }^{1}$. The most common symptom is vaginal bleeding. Many times the colposcopic appearance is non-specific ${ }^{2}$. Histologically, squamous cell carcinoma is common, and classified as non-keratinizing or keratinizing variants ${ }^{1}$.

Histomorphological diagnosis of cervical biopsy can result in under- or over-treatment and low diagnostic agreement rates ${ }^{5}$. Use of P16 as an adjuvant biomarker has improved diagnostic agreement ${ }^{6}$. P16 expression indicates infection with high risk HPV (HR-HPV) and integration of viral genome with host genome ${ }^{4}$. Different pathologists use different criteria and threshold for interpretation of P16 expression ${ }^{7,8}$. Lower anogenital squamous terminology (LAST) criteria defines P16 immunoreactivity as block positive, ambiguous or negative, based on the consideration of P16 expression in the nucleus with or without cytoplasmic staining. The LAST project has been cosponsored by the American Society for Colposcopy and Cervical Pathology (ASCCP) and the College of American Pathologists (CAP). LAST gives standard guidelines for the precise utility of P16 biomarker, decreases interobserver's variation, and increases accuracy $^{8,9}$.

In this study, we have evaluated the association of immunohistochemistry (IHC) P16 biomarker expression and clinico-pathological parameters in our patient population.

\section{MATERIALS - METHODS}

This was a cross-sectional study from October 2017 to September 2018. Ethical clearance was obtained from the Institutional Ethics Committee before the start of the study. A total of 75 clinically suspected and 
histopathologically confirmed cases of SCC of cervix, without radiotherapy or chemotherapy, was considered for the study. The case details such as hospital number, biopsy number, age, presenting complaints, menstrual history, personal history, past history, family history, per-abdominal examination findings, perspeculum examination findings, per-vaginal examination findings, and stage was taken from hospital records. Staging was done per the FIGO staging ${ }^{10}$. Paraffin blocks and the corresponding slides were retrieved from the Department of Pathology. The slides were screened by two pathologists and histological typing was conducted. Histologically, the cases were classified as keratinizing or non-keratinizing types. Keratinizing squamous cell carcinomas was further classified as well-differentiated (WDSCC), moderately differentiated (MDSCC) and poorly differentiated (PDSCC). The non-keratinizing squamous cell carcinomas were further classified as small cell type (NKSCSCC) or large cell type (NKLCSCC) ${ }^{10}$.

Tissue sections were cut from paraffin blocks and evaluated by IHC for P16 marker using a mouse monoclonal anti-p16 ${ }^{I N K 4}$ clone G175-405 as primary antibody (Biogenex, USA); tissue from all 75 cases were evaluated with positive and negative controls. The IHC procedure was carried out per the manufacturer's instructions. The P16 expression on the tissue sections was classified as block positivity, ambiguous staining, or negative per the LAST criteria. "Block" pattern staining corresponded to strong, continuous, nuclear positivity- with or without cytoplasmic staining extending from basal layers upwards for at least $1 / 3^{\text {rd }}$ thickness of the epithelium (basal \& parabasal layers)- which can be further graded as $1 / 3^{r d}, 2 / 3^{r d}$, more than $2 / 3^{r d}$, and laterally over a significant distance with diffuse staining of $>25 \%$ of cells. "Ambiguous" staining corresponded to strong, basal, diffuse and continuous staining (involving only lower $1 / 3^{\text {rd }}$ without upward extension) or weak, diffuse and discontinuous staining (involving at least $2 / 3^{\text {rd }}$ of the epithelium), or strong, focal and discontinuous staining (located at any level of the epithelium). "Negative" staining meant a total absence or weak, focal and discontinuous, or only cytoplasmic staining ${ }^{9}$.

All data were entered in Microsoft Excel, and the data analyzed using SPSS version 22 . The categorical data were presented as frequency and proportions. Continuous data were presented as mean, standard deviation and confidence intervals. Significance of difference between the groups was estimated using standard ' $\mathrm{t}$ ' test and chi-square test; $\mathrm{p}$ value $<0.05$ was considered as statistically significant.

\section{RESULTS}

Seventy-five cases of SCC of cervix were considered for the study. The ages of the cases ranged from 30 80 years with a mean of $54.3 \pm 12.0$. Table 1 shows the age distribution of the cases. Postmenopausal cases and pre- or peri-menopausal cases accounted for $74.7 \%$ and $25.3 \%$, respectively. The majority of women had attained menopause between 40-57 years of age with a mean of $46.3 \pm 3.9$ years. Age range at marriage was $12-23$ years with a mean of $15.7 \pm 2.1$ years; maximum cases were at 15 years $(26.6 \%)$ followed by 14 years $(16 \%)$ of age. Parity ranged from $1-11$ with a mean of $3.6 \pm 1.6$; the cases had a maximum parity of $\geq 5$ (28\%) followed by 4 (26.6\%).

Table 1: Age distribution in cases in present study

\begin{tabular}{cc}
\hline Age Range (years) & Cases \\
$30-39$ & $8(10.6 \%)$ \\
$40-49$ & $19(25.3 \%)$ \\
$50-59$ & $18(24 \%)$ \\
$60-69$ & $19(25.3 \%)$ \\
$70-79$ & $10(13.3 \%)$ \\
$80-89$ & $1(1.3 \%)$ \\
Total & $75(100 \%)$ \\
Total pre and perimenopausal & $19(25.3 \%)$ \\
cases & $56(74.7 \%)$ \\
\hline
\end{tabular}

Clinical presentations of the cases are shown in Table 2, where bleeding per vagina was the common symptom. Per-speculum findings of cases are shown in Table 3, with growth and bleeding as the most common findings. Per-vaginal findings of cases are shown in Table 4. Stages of the disease of the cases are shown in Table 5, with the maximum number of cases in stage III (40\%). The histological grade of disease in the cases are shown in Table 6, with keratinizing SCC as the maximum (90.6\%) compared to non-keratinizing type (9.2\%). Among the keratinizing SCC, the maximum cases were WDSCC (56\%) followed by MDSCC (21.3\%).

Out of 75 cases, P16 expression was block positive, ambiguous or negative in 67 (89.3\%), 5 (6.6\%), and 3 (4\%) cases, respectively. Block positivity was maximal in pre- \& peri-menopausal women $(94.7 \%)$ compared to post-menopausal women $(87.5 \%)$; the differences were not statistically significant $(\mathrm{p}=0.55)$ (Table 7). A statistically significant association was observed between age of cases and P16 expression 


\begin{tabular}{lccc} 
Table 2: Clinical presentation in cases in present study & \\
\hline Clinical Presentation & $\begin{array}{c}\text { Total no of cases } \\
\text { presented } \mathbf{n}=\mathbf{7 5}(\%)\end{array}$ & $\begin{array}{c}\text { Pre \& Peri-menopausal } \\
\text { cases n = 19 (\%) }\end{array}$ & $\begin{array}{c}\text { Post-menopausal cases n } \\
\mathbf{5} \mathbf{5 6}(\%)\end{array}$ \\
Bleeding per vagina & $60(80 \%)$ & $13(68.2 \%)$ & $47(83.9 \%)$ \\
WDPV & $51(68 \%)$ & $10(52.6 \%)$ & $41(73.2 \%)$ \\
Others & $48(64 \%)$ & $11(57.8 \%)$ & $37(66.0 \%)$ \\
Pain Abdomen & $40(53.3 \%)$ & $12(63.1 \%)$ & $28(50.0 \%)$ \\
Post-coital bleeding & $4(5.3 \%)$ & $1(5.2 \%)$ & $3(5.3 \%)$ \\
Mass per vagina & $2(2.6 \%)$ & $1(5.2 \%)$ & $1(1.7 \%)$ \\
No symptoms & $2(2.6 \%)$ & $2(10.5 \%)$ & 00 \\
\hline
\end{tabular}

Table 3: Per-speculum findings in cases in present study

\begin{tabular}{lccc}
\hline Per-speculum findings & Total No. of cases & $\begin{array}{c}\text { Pre \& Peri-menopausal } \\
\text { cases }\end{array}$ & Post-menopausal cases \\
Growth & $49(65.3 \%)$ & $11(57.8 \%)$ & $38(67.8 \%)$ \\
Bleeding & $8(10.6 \%)$ & $2(10.5 \%)$ & $6(10.7 \%)$ \\
Erosion & $6(8 \%)$ & $3(15.7 \%)$ & $3(5.3 \%)$ \\
Ulcer & $5(6.6 \%)$ & $2(10.5 \%)$ & $3(5.3 \%)$ \\
Unhealthy & $3(4 \%)$ & $1(5.2 \%)$ & $2(3.5 \%)$ \\
Mass & $2(2.6 \%)$ & 00 & $2(3.5 \%)$ \\
Stenosis & $1(1.3 \%)$ & 00 & $1(1.7 \%)$ \\
WDPV & $1(1.3 \%)$ & 00 & $1(1.7 \%)$ \\
Total & $75(100 \%)$ & $19(100 \%)$ & $56(100 \%)$ \\
\hline
\end{tabular}

Table 4: Per-Vaginal findings in cases in present study

\begin{tabular}{lccc}
\hline Per vaginal examination & Total No. of cases & $\begin{array}{c}\text { Pre \& Peri-menopausal } \\
\text { cases }\end{array}$ & Post-menopausal cases \\
Friable Growth & $45(60.0 \%)$ & $11(57.8 \%)$ & $34(60.7 \%)$ \\
Induration & $28(37.3 \%)$ & $7(36.8 \%)$ & $21(37.5 \%)$ \\
Erosion & $1(1.3 \%)$ & 00 & $1(1.7 \%)$ \\
Stenosis & $1(1.3 \%)$ & $1(5.2 \%)$ & 00 \\
Total & $75(100 \%)$ & $19(100 \%)$ & $56(100 \%)$ \\
\hline
\end{tabular}

Table 5: Stages of the disease in cases in present study

\begin{tabular}{lccc}
\hline Stage of the disease & Total No of Cases & $\begin{array}{c}\text { Pre \& Peri-menopausal } \\
\text { cases }\end{array}$ & $\begin{array}{c}\text { Post-menopausal cases } \\
\text { Stage I }\end{array}$ \\
Stage II & $6(8 \%)$ & $4(21.0 \%)$ & $2(3.5 \%)$ \\
Stage III & $24(32 \%)$ & $7(36.8 \%)$ & $17(30.5 \%)$ \\
Stage IV & $30(40 \%)$ & $3(15.7 \%)$ & $27(48.2 \%)$ \\
Total & $15(20 \%)$ & $5(26.3 \%)$ & $10(17.8 \%)$ \\
\hline
\end{tabular}


Table 6: Histological grade of the disease in cases in the present study

\begin{tabular}{lccc}
\hline Grade of the disease & No of cases $(\%)$ & $\begin{array}{c}\text { Pre \& Peri-menopausal } \\
\text { cases }\end{array}$ & Post-menopausal cases \\
WDSCC & $42(56 \%)$ & $13(68.4 \%)$ & $29(51.7 \%)$ \\
MDSCC & $16(21.3 \%)$ & $3(15.7 \%)$ & $13(23.2 \%)$ \\
PDSCC & $10(13.3 \%)$ & $1(5.2 \%)$ & $09(16.1 \%)$ \\
NKLCSCC & $5(6.6 \%)$ & $2(10.5 \%)$ & $3(5.3 \%)$ \\
NKSCSCC & $2(2.6 \%)$ & - & $2(3.5 \%)$ \\
Total & $75(100 \%)$ & $19(100 \%)$ & $56(100 \%)$ \\
\hline
\end{tabular}

$(\mathrm{p}=0.005)$ (Table 8). All cases $(100 \%)$ between 30 59 years of age showed block positivity. There was no significant association between age at marriage of cases and P16 expression ( $\mathrm{p}=0.951$ ) (Table 9). The p16 expression was maximum among females with age of marriage between 15 and 18 years. There was no statistically significant association between age at menopause of cases and P16 expression ( $p=0.311$ ) (Table 10). Among the post-menopausal women, P16 expression was maximal between $40-44$ years. There was no significant association $(p=0.554)$ between parity and P16 expression. However, all cases (100\%) with parity one and two showed block positive P16 expressions (Table 11).

There was no significant association between P16 expression and clinical presentation $(\mathrm{p}=0.135)$, or perspeculum examination findings $(p=0.217)$, or pervaginal examination findings $(p=0.982)$. There was no significant association between P16 expression and stage of the disease $(\mathrm{p}=0.28)$ (Table 12). However, all stage I cases (100\%) showed block positive P16 expression. There was no significant association between histopathological grade and P16 expression ( $\mathrm{p}$ $=0.877$ ) (Table 13). However, most of the cases of WDSCC (88.0\%) and MDSCC (93.7\%) showed block positive $\mathrm{P} 16$ expression, though there was no statistical significance.

\section{DISCUSSION}

Cervical cancer is one of the most common cancers in women worldwide, especially in women from developing countries. It is the most common cause of cancer-related deaths in females. The prevalence of cervical cancer in the Southeast part of Karnataka (India) at a tertiary health care center is $17 \%$ of the total cancers of females ${ }^{11}$. The prevalence reported at Bangalore by the Kidwai Memorial Institute of Oncology between $2004-2005$ was $15.9 \%{ }^{12}$. The National Cancer Registry Program newsletter has reported the incidence to be $6.2 \%$ - $22.6 \%$ between $2001-2011$ in India and $21.1 \%$ in Bangalore ${ }^{13}$.

Pap smear test as a screening test has helped decrease the incidence of cervical cancer by $75 \%$, especially in developed countries. However, it has some limitations such as low sensitivity, false negative results and low reproducibility. To overcome this, the P16 biomarker has been used as an alternative and has emerged as a surrogate marker for in-situ as well as advanced cervical cancer. The P16 biomarker test has better reproducibility. The $\mathrm{P} 16$ gene undergoes alterations like amplification following HPV infection and integration of viral genome with host genome. P16 may also undergo mutations ${ }^{14,15}$. Normally, the expression of P16 increases with age which results in a decrease of the renewal activity of stem cells. In conditions of inhibition / low P16 expression, there will be high expression of cancer stem cells which results in increased ability of self-renewal of cancer stem cells ${ }^{16}$. The sensitivity, specificity and accuracy of P16 biomarker to diagnose SCC of cervix is $96.0 \%, 88.2 \%$ and $91.7 \%$, respectively ${ }^{17}$.

In the present study, IHC P16 expression per the LAST classification showed block positivity in 67 cases $(89.3 \%)$, ambiguity in 5 cases $(6.6 \%)$ and negativity in 3 cases (4\%). In a study by Sarwath $\mathrm{H}$ et al., block positivity was seen in $92.2 \%$ of cases and negativity in $7.8 \%$ of cases, with sensitivity, specificity, PPV and NPV of $79.2 \%, 46 \%, 83.9 \%$ and $27.2 \%$, respectively. The absence of P16 expression in SCC of cervix may be due to absence of HPV infection, improper IHC technique, mutations in promoter region, epigenetic mechanisms and hypermethylation ${ }^{1}$. Stoler MH et al. classified P16 expression as diffuse, focal and negative per the LAST criteria and found that P16 expression was diffuse in $100 \%$ of invasive cancers ${ }^{6}$. Amaro-Filho has reported P16 expression as diffuse, focal and negative in $85.5 \%, 9.9 \%$ and $4.6 \%$ 
Table 7: P16 expression as per LAST criteria in cervical biopsy by IHC in the present study

\begin{tabular}{lccc}
\hline P16 expression & No of Cases (\%) & $\begin{array}{c}\text { Pre \& Peri-menopausal } \\
\text { cases }\end{array}$ & Post-menopausal cases \\
Negative & $3(4 \%)$ & 00 & $3(5.3 \%)$ \\
Ambiguity & $5(6.6 \%)$ & $1(5.2 \%)$ & $4(7.1 \%)$ \\
Block Positive & $67(89.3 \%)$ & $18(94.7 \%)$ & $49(87.5 \%)$ \\
Total & $75(100 \%)$ & $19(100 \%)$ & $56(100 \%)$ \\
\hline
\end{tabular}

P value of P16 expression between pre \& peri-menopausal and post-menopausal cases was 0.555

Table 8: Association between age distribution in cases and P16 expression in the present study

\begin{tabular}{lcccc}
\hline Age range of cases & \multicolumn{2}{c}{ Expression of P16 (n) } \\
& Negative & Ambiguous & Block positivity & Total cases \\
$30-39$ & 0 & 0 & 8 & 8 \\
$40-49$ & 0 & 0 & 19 & 19 \\
$50-59$ & 0 & 0 & 18 & 18 \\
$60-69$ & 2 & 3 & 14 & 19 \\
$70-79$ & 1 & 1 & 8 & 10 \\
$80-89$ & 0 & 1 & 0 & 1 \\
Total cases & 3 & 5 & 67 & 75 \\
\hline
\end{tabular}

$\mathrm{P}$ value between age of cases and P16 expression was 0.005

Table 9: Association between age at marriage in cases and P16 expression in the present study

\begin{tabular}{lcccc}
\hline Age at menopause & & \multicolumn{2}{c}{ Expression of P16 (n) } \\
& Negative & Ambiguous & Block positivity & Total cases \\
$12-14$ years & 1 & 1 & 17 & 19 \\
15 to 18 years & 2 & 4 & 46 & 52 \\
$>18$ years & 0 & 0 & 4 & 4 \\
Total cases & 3 & 5 & 67 & 75 \\
\hline
\end{tabular}

P value between age of cases and P16 expression was 0.951

Table 10: Association between age at menopause in cases and P16 expression in the present study

\begin{tabular}{lcccc}
\hline Age at menopause & & \multicolumn{2}{c}{ Expression of P16 (n) } \\
& Negative & Ambiguous & Block positivity & Total cases \\
Peri \& Post-menopausal & 0 & 1 & 18 & 19 \\
$40-44$ & 0 & 1 & 15 & 22 \\
$45-49$ & 2 & 1 & 11 & 13 \\
$50-54$ & 1 & 1 & 1 & 2 \\
$55-59$ & 0 & 1 & 67 & 75 \\
Total cases & 3 & 5 & & 25 \\
\hline
\end{tabular}

P value between age at menopause of cases and P16 expression was 0.311 
Table 11: Association between parity in cases and P16 expression in the present study

\begin{tabular}{lcccc}
\hline \multirow{2}{*}{ Para of cases } & \multicolumn{2}{c}{ Expression of P16 (n) } \\
& Negative & Ambiguous & Block positivity & Total cases \\
Para 1 & 0 & 0 & 6 & 6 \\
Para 2 & 0 & 0 & 11 & 11 \\
Para 3 & 0 & 1 & 16 & 17 \\
Para 4 & 1 & 3 & 16 & 20 \\
Para $\geq 5$ & 2 & 1 & 18 & 21 \\
Total cases & 3 & 5 & 67 & 75 \\
\hline
\end{tabular}

P value between parity of cases and P16 expression was 0.554

Table 12: Association between stage of disease and P16 expression in the present study

\begin{tabular}{lcccc}
\hline & & \multicolumn{2}{c}{ Expression of P16 (n) } \\
Stage of disease & Negative & Ambiguous & Block positivity & Total cases \\
Stage I & 0 & 0 & 6 & 6 \\
Stage II & 2 & 1 & 21 & 24 \\
Stage III & 1 & 1 & 28 & 30 \\
Stage IV & 0 & 3 & 12 & 15 \\
Total cases & 3 & 5 & 67 & 75 \\
\hline
\end{tabular}

P value between stage of disease and P16 expression was 0.285

Table 13: Association between histopathology grades in cases and P16 expression in the present study

\begin{tabular}{|c|c|c|c|c|}
\hline \multirow[t]{2}{*}{ Para of cases } & \multicolumn{4}{|c|}{ Expression of P16 (n) } \\
\hline & Negative & Ambiguous & Block positivity & Total cases \\
\hline NKSCSCC & 0 & 0 & 2 & 2 \\
\hline NKLCSCC & 0 & 1 & 4 & 5 \\
\hline PDSCC & 0 & 1 & 9 & 10 \\
\hline MDSCC & 1 & 0 & 15 & 16 \\
\hline WDSCC & 2 & 3 & 37 & 42 \\
\hline Total cases & 3 & 5 & 67 & 75 \\
\hline
\end{tabular}

P value between parity of cases and P16 expression was 0.877

cases, respectively, in SCC of cervix; the data were statistically significant $(\mathrm{p}<0.001)^{18}$.

In the present study, there was a statistically significant association between age and P16 expression, where all cases (100\%) between 30-59 years showed block positivity. Pre- and peri-menopausal women showed maximal (94.73\%) block positivity over post-menopausal women; the data was not statistically significant. Among the post-menopausal women, women between 40-44 years showed maximal (93.75\%) block positivity, although this data was not statistically significant. Sarwath et al. stated that there was a significant correlation between P16 expression and age group between $41-60$ years. This was thought to be due to active transforming precancerous lesions in younger age group women. Hence, P16 is an appropriate surrogate marker for use in early screening of cervical cancer ${ }^{1}$.

In the present study, parity and P16 expression did not show a statistically significant association. However, all cases (100\%) with parity one and two showed block positivity. There was no statistically significant association between stage / histological grade of the disease and P16 expression. However, all stage 
I cases $(100 \%)$ showed block positivity and a majority of cases of WDSCC (88.0\%) and MDSCC (93.7\%) showed block positivity. Fu HC et al. in their study stated that P16 expression was not found to have an association with tumor stage, tumor size, histological grade, vascular invasion, CEA levels, SCC Ag levels, or non-squamous cell carcinoma. The independent prognostic factors for cervical cancer regarding disease-free survival (DFS) is high-grade SCC, non-SCC and low P16 expression ${ }^{16}$. Sarwath et al. stated that P16 expression did not correlate with tumor grade and size of the tumor ${ }^{1}$. Huangfu $\mathrm{M}$ et al. in their study reported that auto-antibodies against P16 protein (tumor-associated antigen) are released in cases of cervical cancer, and they are found to be at the highest levels in serum of stage I cervical cancer patients, with sensitivity of $>90 \%$ and specificity of $20.3 \%$. Hence, P16 auto-antibody can be used as one of the parameters for early diagnosis and assessment of prognosis ${ }^{19}$.

Cervical cancer with P16 expression has better prognosis ${ }^{16,20}$. High P16 expression in cervical cancer is reported to have high five-year overall survival and DFS, both of which were statistically significant. Fiveyear overall survival in high and low P16 expression was $62.0 \%$ and $35.2 \%$, respectively. DFS in high and low P16 expression was $60.0 \%$ and $31.2 \%$, respectively ${ }^{16,20}$. In the present study, the cases were not followed up for prognosis. P16 is also an indicator for radiosensitivity. Thus, due to its anti-cancer activity, P16 can be exploited for development of targeted chemotherapy in cervical cancer ${ }^{16}$.

The limitation of the present study was that we did not follow up with the cases to assess their prognosis. However, P16 block positivity was high in young females and was statistically significant. P16 expression was maximal in pre- and peri-menopausal females, post-menopausal females between $40-44$ years of age, females with one/two parity and in stage I disease, although these were not statistically significant. The study can be conducted in a larger population to further confirm the above findings.

\section{CONCLUSION}

Significant p16 biomarker expression was observed in cervical patients of younger age and early stage of the disease. Therefore, P16 biomarker may have a beneficial use in screening or early diagnosis leading to better prognosis of SCC of cervix. This findings from the study can also be used as a concept for targeted therapy as $\mathrm{P} 16$ protein has anti-cancer properties.

\section{ABBREVIATIONS}

Ag: Antigen

ASCCP: American Society for Colposcopy and Cervical Pathology

CAP: College of American Pathologists

CEA: Carcinoembryonic Antigen

DFS: Disease Free Survival

FIGO: International Federation of Gynaecology and Obstetrics

HPV: Human Papilloma Virus

HR-HPV: High Risk Human Papilloma Virus

IHC: Immunohistochemistry

LAST: Lower Anogenital Squamous Terminology

MDSCC: Moderately Differentiated Squamous Cell Carcinoma

NKLCSCC: Non-Keratinizing Large Cell Squamous Cell Carcinomas

NKSCSCC: Non-Keratinizing Small Cell Squamous Cell Carcinomas

PDSCC: Poorly Differentiated Squamous Cell Carcinoma

SCC: Squamous Cell Carcinoma

WDSCC: Well Differentiated Squamous Cell Carcinoma

\section{ACKNOWLEDGMENTS}

Nil

\section{AUTHOR'S CONTRIBUTIONS}

Kalyani Raju: Concept, Study design, data collection, literature search, statistical analysis, manuscript writing, manuscript editing. Raghuveer CV: Concept, Manuscript editing, manuscript review. Sheela SR: Data collection, manuscript editing.

\section{FUNDING}

Nil

\section{AVAILABILITY OF DATA AND MATERIALS}

Data and materials used and/or analyzed during the current study are available from the corresponding author on reasonable request.

\section{ETHICS APPROVAL AND CONSENT TO PARTICIPATE}

This study was conducted in accordance with the amended Declaration of Helsinki. The institutional review board (The Institutional Ethics Committee of Sri Devaraj Urs Medical College, Tamaka, Kolar) approved the study, and all participants provided written informed consent. 


\section{CONSENT FOR PUBLICATION}

Not applicable.

\section{COMPETING INTERESTS}

The authors declare that they have no competing interests.

\section{REFERENCES}

1. Sarwath $H$, Bansal D, Husain NE, Mohamed M, Sultan AA, Bedri S. Introduction of p16INK4a as a surrogate biomarker for HPV in women with invasive cervical cancer in Sudan. Infectious Agents and Cancer. 2017;12:50. PMID: 29021820. Available from: https://doi.org/10.1186/s13027-017-0159-0.

2. Esmaeili HA, Pourlak T, Ghamari B, Shayan FK, SanaatZ, Soltani GG, Fattahi S. Comparison of nuclear P16 immunostaining in atypical and normal endocervical glands: A descriptive analytical study. J Anal Res Clin Med . 2018;6(2):66-71. Available from: https://doi.org/10.15171/jarcm.2018.010.

3. Jacob AA, Sundaram A. P16, Ki67 and P63 staining pattern in squamous metaplasia, CIN andcervical cancer. Int J Res Med Sci. 2018;6(3):882-888. Available from: https://doi.org/ 10.18203/2320-6012.ijrms20180608.

4. Gonçalves JES, de Andrade CV, Russomano FB, Nuovo GJ, Amaro-Filho SM, Carvalho MOO, Nico AF. The role of p16 as putative biomarker for cervical neoplasia: A controversial issue? Medical Express (Sao Paulo, online). 2017;4(6):M170601. Available from: https://doi.org/10.5935/MedicalExpress.2017. 06.01 .

5. Ahmed SA, Obaseki DE, Mayun AA, Mohammed A, Rafindadi $\mathrm{AH}$, Abdul MA. The Role of Biomarkers (p16INK4a and Ki-67) in Cervical Cancer Screening: An Appraisal. Ann Trop Pathol. 2017;8:1-4. Available from: https://doi.org/10.4103/atp.atp_3_ 17.

6. Stoler MH, Wright Jr TC, Ferenczy A, Moore JR, Fang O, Kapadia M, Ridder R. Routine Use of Adjunctive p16 Immunohistochemistry Improves Diagnostic Agreement of Cervical Biopsy Interpretation Results From the CERTAIN Study. Am J Surg Pathol. 2018;42:1001-1009. PMID: 29697437. Available from: https://doi.org/10.1097/PAS.0000000000001072.

7. Singh C, Manivel JC, Truskinovsky AM, Savik K, Amirouche S, Holler J, Thyagarajan B, Gulbahce HE, Pambuccian SE. Variability of Pathologists' Utilization of p16 and Ki-67 Immunostaining in the Diagnosis of Cervical Biopsies in Routine Pathology Practice and Its Impact on the Frequencies of Cervical Intraepithelial Neoplasia Diagnoses and Cytohistologic Correlations. Arch Pathol Lab Med. 2014;138:76-87. PMID: 24377814. Available from: https://doi.org/10.5858/arpa.2012-0472-OA.

8. Clark JL., Lu D, Kalir T, Liu Y. Over diagnosis of HSIL on Cervical Biopsy: Errors in P16 Immunohistochemistry Implementation. Human Pathology. 2016;55:51-56. PMID: 27134110. Available from: https://doi.org/10.1016/j.humpath.2016.04.010.

9. Darragh TM, Colgan TJ, Thomas Cox JT, Heller DS, He nry MR, Luff RD, et al. The Lower Anogenital Squamous Terminology Standardization Project for HPV-Associated Lesions: Background and Consensus Recommendations from the Col- lege of American Pathologists and the American Society for Colposcopy and Cervical Pathology. Arch Pathol Lab Med. 2012;136:1-33. PMID: 22742517. Available from: https://doi. org/10.5858/arpa.LGT200570.

10. Stoler M, Bergeron C, Colgan TJ, Ferenczy AS, Herrington CS Kim KR, et al. Squamous cell tumors and precursors.In, Kurman $\mathrm{RJ}$, Carcangin ML, Herrington CS, Young RH (ed). WHO classification of tumors of female reproductive organs, 4th edition;

11. Kalyani R, Das S, Singh Bindra MS, Kumar HML. Cancer profile in department of pathology of Sri Devaraj Urs Medical College, Kolar: a Ten Years Study. Indian journal of Cancer. 2010;47(2):160-165. PMID: 20448380. Available from: https: //doi.org/10.4103/0019-509X.63011.

12. Ramesh C. Department of Epidemiology and Biostatistics, (Hospital Based Cancer Registry) Kidwai Memorial Institute of Oncology ;Available from: http://www.kidwai.kar.nic.in/ statistics.htm.

13. Takiar R, Shrivastava A, Nadayil D. The impact of census 2011 data on cancer incidence rates in registries under NCRP - first observations. Cancer Registry Abstract (CRAB), The newsletter of NCRP. 2011;XVI(1):6-11.

14. Yang HJ, Liu VWS, Wang Y, Chan KYK, Tsang PCK, Khoo US, Cheung ANY, Ngan HYS. Detection of hypermethylated genes in tumor and plasma of cervical cancer patients. Gynecologic Oncology. 2004;93:435-440. PMID: 15099958. Available from: https://doi.org/10.1016/j.ygyno.2004.01.039.

15. Sun $M$, Shen $Y$, Ren ML, Dong YM. Meta-analysis on the performance of p16/Ki-67 dual immunostaining in detecting highgrade cervical intraepithelial neoplasm. J Can Res Ther. 2018;14:S587-S593. PMID: 30249873. Available from: https: //doi.org/10.4103/0973-1482.183216.

16. Fu HC, Chuang IC, Yang YC, Chuang PC, Lin H, Ou YC, et al . Low P16INK4A Expression Associated with High Expression of Cancer Stem Cell Markers Predicts Poor Prognosis in Cervical Cancer after Radiotherapy. Int J Mol Sci. 2018;19:2541. PMID: 30150594. Available from: https://doi.org/10.3390/ ijms19092541.

17. Wu MZ, Wang S, Zheng M, Tian LX, Wu X, Guo KJ, Zhang Y, Wu GP. The Diagnostic Utility of p16 Immunostaining in Differentiating Cancer and HSIL from LSIL and Benign in Cervical Cells. Cell Transplantation. 2019;28(2):195-200. PMID: 30545241. Available from: https://doi.org/10.1177/0963689718817478.

18. Amaro-Filho SM, Golub JE, Nuovo GJ, Cunha CB, Levi JE, Villa $\mathrm{LL}$, et al. A Comparative Analysis of Clinical and Molecular Factors with the Stage of Cervical Cancer in a Brazilian Cohort. Plos One. 2013;8:1-10. PMID: 23505442. Available from: https://doi.org/10.1371/journal.pone.0057810.

19. Huangfu M, Liu L, Xu S, Li S, Jiang K, Sun B, et al. Detecting of p16 Autoantibody as a Potential Early Diagnostic Serum Biomarker in Patients with Cervical Cancer. Clin Lab. 2016;62(6):1117-1120. PMID: 27468574. Available from: https://doi.org/10.7754/Clin.Lab.2015.151024.

20. Tainio $K$, Athanasiou A, Tikkinen $K A O$, Aaltonen $R$, Hernandes JC, Livson SG, et al. Clinical course of untreated cervical intraepithelial neoplasia grade 2 under active surveillance: systematic review and meta-analysis. BMJ. 2018;360:k499. PMID: 29487049. Available from: https://doi.org/10.1136/bmj.k499. 